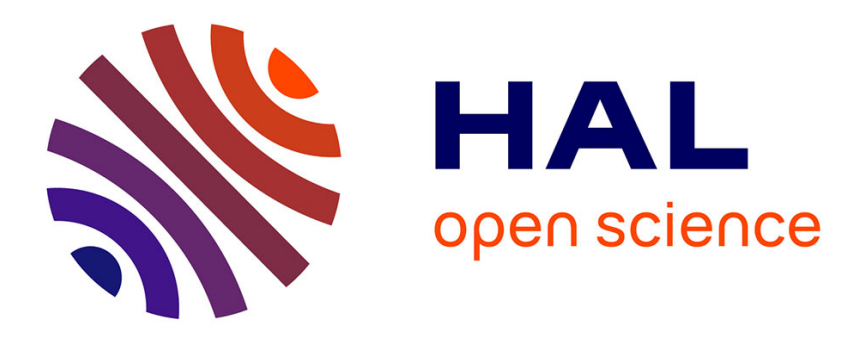

\title{
Microstructural Characterization of Ion Implanted Polycrystalline Alumina
}

\author{
A. Rahioui, C. Esnouf, T. Girardeau, A. Benyagoub
}

\section{To cite this version:}

A. Rahioui, C. Esnouf, T. Girardeau, A. Benyagoub. Microstructural Characterization of Ion Implanted Polycrystalline Alumina. Journal de Physique III, 1996, 6 (5), pp.613-623. 10.1051/jp3:1996144 . jpa-00249480

\section{HAL Id: jpa-00249480 https://hal.science/jpa-00249480}

Submitted on 1 Jan 1996

HAL is a multi-disciplinary open access archive for the deposit and dissemination of scientific research documents, whether they are published or not. The documents may come from teaching and research institutions in France or abroad, or from public or private research centers.
L'archive ouverte pluridisciplinaire HAL, est destinée au dépôt et à la diffusion de documents scientifiques de niveau recherche, publiés ou non, émanant des établissements d'enseignement et de recherche français ou étrangers, des laboratoires publics ou privés. 


\title{
Microstructural Characterization of Ion Implanted Polycrystalline Alumina
}

\author{
A. Rahioui $\left(\left(^{1, *}\right)\right.$, C. Esnouf $\left({ }^{1}\right)$ T. Girardeau $\left({ }^{2}\right)$ and A. Benyagoub $\left({ }^{3}\right)$ \\ ( $\left.{ }^{1}\right)$ Groupe de Métallurgie Physique et de Physique des Matériaux (GEMPPM) $\left(^{* *}\right.$ ), \\ Bâtiment 502 - INSA, 69621 Villeurbanne Cedex, France \\ $\left({ }^{2}\right)$ Laboratoire de Métallurgie Physique (LMP) $\left(^{* * *}\right)$, SP2MI, BP 179, \\ 86960 Futuroscope Cedex, France \\ $\left({ }^{3}\right)$ Institut de Physique Nucléaire de Lyon (IPN) $\left({ }^{* * *}\right), 69622$ Villeurbanne Cedex, France
}

(Received 28 June 1995, revised 12 January 1996, accepted 24 January 1996)

PACS.61.80.Jh - Ion radiation effects

\begin{abstract}
The microstructural changes induced in polycrystalline $\alpha$-alumina by high dose ion implantation were studied by Transmission Electron Microscopy (TEM) and X-ray Absorption Near-Edge Structure (XANES). Several regions were observed in the specimens prepared by the cross-sectional method. We found that the implanted layer consists of a strongly damaged crystallographic structure, which tends to be destabilized in a cubic structure, where the atomic sites are very strained. The layer beyond the distribution of implanted ions is characterized by a high density of defects. A mechanism explaining the formation of this defective layer is proposed.
\end{abstract}

\section{Introduction}

Ion implantation is one of the most promising methods for altering the near surface properties of a wide range of materials, notably ceramics $[1,2]$. However, it is important to understand the microstructural evolution leading to these modifications. The interaction of an energetic ion beam with an insulator differs from that of a metal in several significant ways. Insulators are generally composed of two or more chemical species that are distributed over at least two sublattices usually in an ordered fashion. The chemical bonding of their atoms presents a mixed character running from ionic to covalent type. The aluminium oxide is qualified as an iono-covalent ceramic since the two bonding types are nearly equally partaged. Atoms of one species, which are displaced by the elastic collisions with the incident ions, do not likely come to rest at the lattice sites of the other species. The species (aluminium and oxygen) have different atomic masses and the energy needed to displace each species from its lattice site may be very different. In the case of alumina, the displacement energies for aluminium and oxygen are quite different, being 18 and $72 \mathrm{eV}$, respectively [3].

$\left(^{*}\right)$ Author for correspondence (Fax: (33) 72438528 )

$\left.{ }^{(* *}\right)$ UMR 5510

$\left({ }^{* * *}\right)$ URA CNRS 131

$\left(^{* * * *}\right)$ UMR 6422

(C) Les Éditions de Physique 1996 
Our objective is to understand the structural evolution of the $a-\mathrm{Al}_{2} \mathrm{O}_{3}$ atomic edifice when submitted to high-dose ion implantation. Several techniques are used to study this evolution. TEM enables direct observation and quantification of the microstructure in terms of phase formation, lattice damage, crystallinity of the implanted layer, using the conventional imaging and diffraction methods. Since the regions of interest in implanted insulators are located within several tens of nanometers from the surface, it is useful to examine both cross-sectional and back-thinned (plan view) specimens in order to obtain a more complete understanding of the developed microstructure and its relationship to the surface. Moreover, in order to complete the characterization of the implanted layer, it was important to use other techniques providing information at an atomic scale. A possibility lies in the use of the EXAFS (Extended X-ray Absorption Fine Structure) technique, which enables to characterize the local environment of the probed atoms. In another hand, the XANES (X-ray Absorption Edge Structure) technique gives information about the surrounding cage (i.e., the site) of atoms. In our case, the atomic distribution in $\alpha$-alumina oxide is complex and does not give significant EXAFS spectra (in a cristallographically perfect alumina, aluminium atoms are distributed over distorted octahedral sites composed of oxygen atoms). Due to this fact, we have used the XANES technique.

\section{Experimental Details}

In this study the microstructural investigations of the near surface region were directly performed on polycrystalline $\alpha$-alumina samples having a mean grain size of about $2 \mu \mathrm{m}$. This size is very high in comparison with the collision cascade volume so that we can assume that the implantation damage is not affected by grain boundaries.

Ion implantations on $a-\mathrm{Al}_{2} \mathrm{O}_{3}$ samples (purity $=99.99 \%$ ) were carried out in IPN-Lyon. The specimens were preliminarily polished and annealed in air for one hour at $1120 \mathrm{~K}$. The implantations were performed at room temperature with $\mathrm{Cu}, \mathrm{Zr}$ or Fe ions, under various ion incident energies (50, 110 and $220 \mathrm{keV}$ ) and at a fluence of $10^{17}$ at $\mathrm{cm}^{-2}$ The beam current density was about $10 \mu \mathrm{A} \mathrm{cm} \mathrm{cm}^{-2}$.

$\mathrm{Cu}, \mathrm{Zr}$ and Fe species were chosen because of the great difference of their oxydation enthalpy and valence number in comparison with the aluminium ones. As shown in Table I, $\mathrm{Zr}$ and $\mathrm{Al}$ species have nearly the same oxydation level. Cu species are the less oxidizable ones, while iron presents an intermediate case.

Microscopy was performed at GEMPPM using a JEOL $200 \mathrm{CX}$ machine equipped with STEM (Scanning Transmission Electron Microscopy) and EDS (X-ray Energy Dispersive Spectroscopy) accessories. Specimens for TEM were prepared in both cross-section and backthinned methods by mechanical polishing (dimpler grinding) followed by ion milling. Details for the specimen preparation have been published elsewhere $[4,5]$.

XANES spectra collected near the absorption K-edge of aluminium were obtained at LURE (Laboratoire d'Utilisation du Rayonnement Électromagnétique) in Orsay, where synchrotron radiation is available in the energy range $0.8-2.5 \mathrm{keV}$ (the absorption edge of aluminium is $\approx 1.570 \mathrm{keV}$ ). In order to detect the signals arising from the implanted layer only, we have

Table I. - Oxydation enthalpy of alumınzum and implanted specres.

\begin{tabular}{|c|c|c|c|c|c|}
\hline Oxide & $\mathrm{Al}_{2} \mathrm{O}_{3}$ & $\mathrm{ZrO}_{2}$ & $\mathrm{Cu}_{2} \mathrm{O}$ & $\mathrm{Fe}_{2} \mathrm{O}_{3}$ & $\mathrm{Fe}_{3} \mathrm{O}_{4}$ \\
\hline $\begin{array}{c}\text { Gibbs energy of formation } \\
(\mathrm{kJ} / \mathrm{mol}) \text { at } 300 \mathrm{~K}\end{array}$ & -1060 & -1030 & -290 & -490 & -500 \\
\hline
\end{tabular}


collected the emitted electrons under the impact of synchrotron radiation (total electron yield detection). These electrons are emitted from a small depth (about $30 \mathrm{~nm}$ ). In order to match the analysed depth with the implanted one, an ion energy of $50 \mathrm{keV}$ has been chosen in the case of the XANES study. At this energy, the depth corresponding to a significantly high concentration of implanted ions is actually about $30 \mathrm{~nm}$.

In order to monitor the evolution of the structure of the implanted samples, we have prepared samples of different well-known structures to be used as standards in the XANES technique.

\section{Results}

The examination of the samples implanted with copper at room temperature (110 keV $-10^{17}$ at $\mathrm{cm}^{-2}$ ), and prepared in cross-section view, reveals a microstructure consisting of several regions (Fig. 1). The circled zones show the electron beam impact of the microscope in STEM mode (mean probe size $\approx 40 \mathrm{~nm}$ ). With such an electron beam size, it is possible to determine the local crystallographic aspects by using the SAD (Selected Area Diffraction) technique. Circle (1) is situated on the substrate $\alpha-\mathrm{Al}_{2} \mathrm{O}_{3}$, and circle (4) on the implanted layer, while circle (3) is localized on an intermediate layer between the substrate and the implanted layer. The diffraction conditions were chosen in order to put in contrast (Fig. 1a) the intermediate layer.

EDS spectra from these regions are described in Figure 1b. They reveal that copper is not present in region (3). In consequence, this layer is not directly affected by the implanted species but results from a high density of crystalline defects in the alumina substrate. Its thickness reaches $45 \mathrm{~nm}$, while that of the implanted layer is $85 \mathrm{~nm}$. We will discuss in more details this point afterwards.

Crystallographic evolution of alumina is shown in Figure 2 which presents the electron diffraction patterns obtained in the four regions indicated in Figure 1. The diffraction pattern of region (1) corresponds to the [401] zone axis of $\alpha-\mathrm{Al}_{2} \mathrm{O}_{3}$. Interplanar spacing associated with the high intensity wave $(1 \overline{1} 0 \overline{4})$ is equal to $d=0.255 \mathrm{~nm}$, while the $(0 \overline{3} 30)$ spot corresponds to a $0.137 \mathrm{~nm}$ spacing.

The examination of the diffraction pattern from region 2 shows new spots (arrowed 1, while spots quoted 0 are those of the previous pattern) associated with interplanar spacing of 0.153 $\mathrm{nm}$. This pattern is not consistent with that of $\alpha$-alumina crystal. Indeed, the spot associated with $0.153 \mathrm{~nm}$ and $0.255 \mathrm{~nm}$ spacings can form a coherent pattern of $[2 \overline{2} 1] \quad a-\mathrm{Al}_{2} \mathrm{O}_{3}$ zone axis, but it should contain other high intensity spots such as $(11 \overline{2} 0)$ and $(01 \overline{1} 2)(d=0.238 \mathrm{~nm}$ and $0.348 \mathrm{~nm}$ respectively) which are not observed. Moreover, it would be very surprising that the initial zone axis [401] can be transformed into a [2 21 ] zone axis. Consequently, a structural anomaly is detected at the approach of the defective layer 3 .

As seen in Figure 2, the diffraction pattern originated from region 3 is more complicated, it reveals spots which do not necessarily correspond to a same crystal. Same interlattice distances as that indicated previously by spot 1 are detected, but other distances appear (arrowed 2, 3, 4) (see Tab. II). The diffraction pattern 4 taken from the implanted layer presents rings similar to Debye-Scherrer pattern type. The width of rings (specially those arrowed by 1 ) is too small to allow to conclude that an amorphisation has taken place. In fact the implanted layer is made of a very high density of small crystals such that no grain boundaries are detectable. The rings of this pattern correspond to the same distances as those which have been seen in the previous pattern of region 3, except for the ring arrowed $\mathrm{Cu}$ (spacing $0.209 \mathrm{~nm}$ ). It is attributed to spots $\{111\}$ of copper (which has a high structure factor value for these waves). This result demonstrates that copper clusters are formed during ion implantation into alumina, their mean size is $\sim 3 \mathrm{~nm}[5,6]$. 

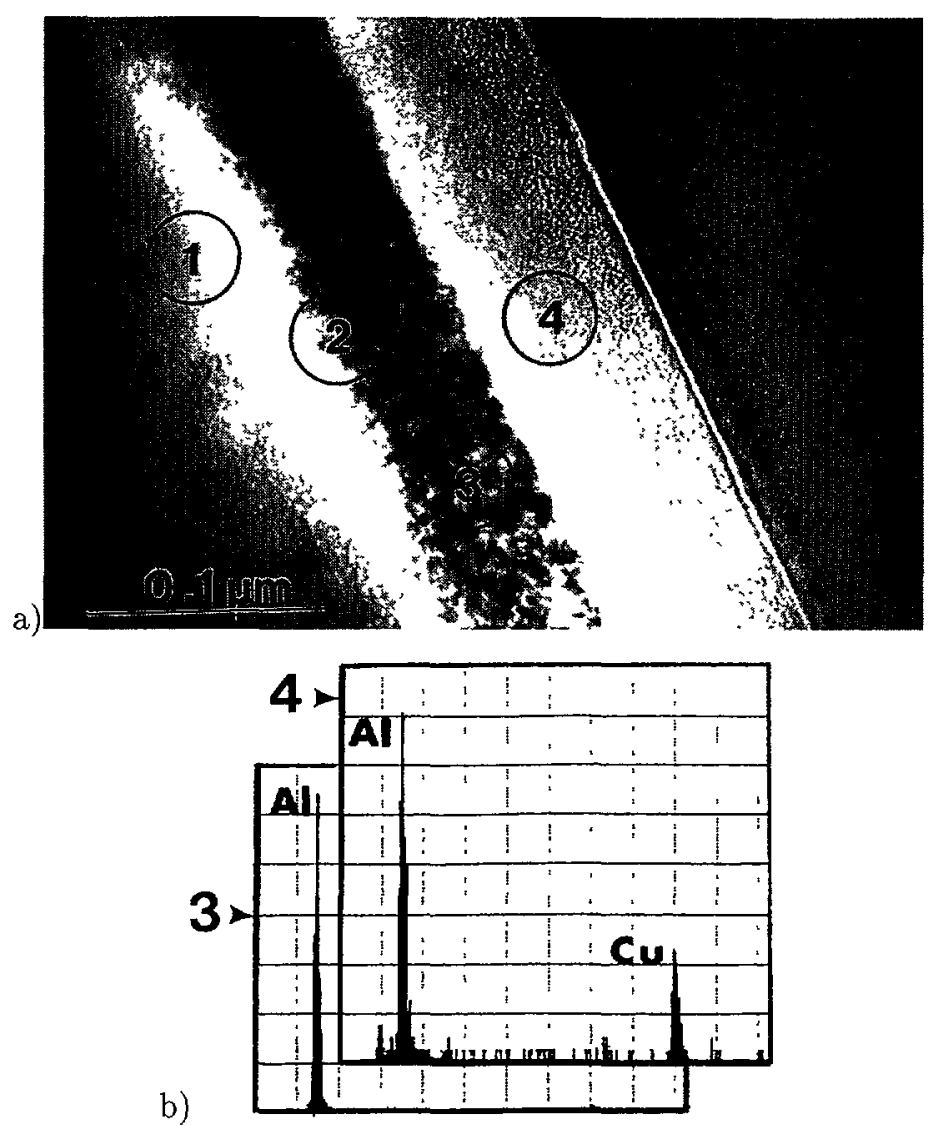

Fig. 1. - a) Cross-section micrograph showing the microstructure of the near surface region of $\alpha-\mathrm{Al}_{2} \mathrm{O}_{3}$ following an implantation at room temperature with $\mathrm{Cu}$ ions $\left(110 \mathrm{keV}, 10^{17}\right.$ at $\left._{\mathrm{cm}}{ }^{-2}\right)$. Three distinct regions are observed in the cross-section micrograph. b) EDS spectra obtained from the implanted layer (labelled 4) and the defective layer (labelled 3).

Table II. - Interplanar spacings calculated from the diffraction patterns shown in Figure 2.

\begin{tabular}{|l|l|}
\hline spot 0 & $d_{0}=0.137 \mathrm{~nm}$ \\
\hline spot 1 & $d_{1}=0.153 \mathrm{~nm}$ \\
\hline spot 2 & $d_{2}=0.265 \mathrm{~nm}$ \\
\hline spot 3 & $d_{3}=0.300 \mathrm{~nm}$ \\
\hline spot 4 & $d_{4}=0.255 \mathrm{~nm}$ \\
\hline
\end{tabular}

The outside ring corresponds to a spot noted 1 in pattern 3 , while the central diffuse ring includes spots 2 and 3. From measurements of interplanar spacing collected in Table II and pattern 3, we can notice that the position of spots 3 is at half the spacing of spots 1 (giving the 

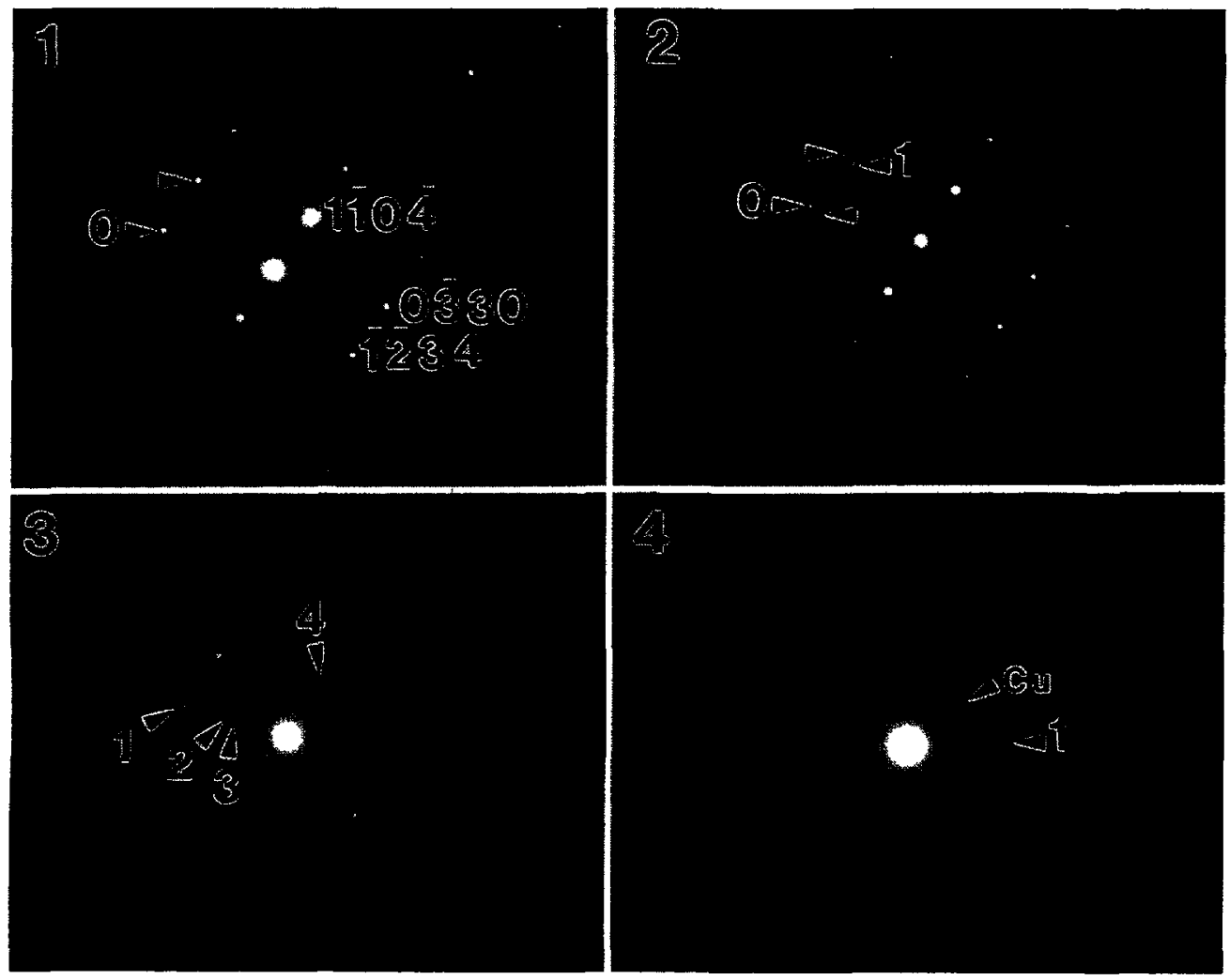

Fig. 2. - Diffraction patterns (electron beam size $=40 \mathrm{~nm}$ ). Numbers indicate the regions described in the micrograph of Figure 1.

relation $d_{3} \approx 2 d_{1}$ between their interplanar distances), and that spots 2 lie in the mid-spacing of the spots associated with the substrate and noted 0 in pattern 2 (so, $d_{2} \approx 2 d_{0}$ ).

Moreover, using the dark fied imaging from a part of ring 1, a structure of elongated grains is observed on the borders of the implanted layer. For instance, the superficial region (about $20 \mathrm{~nm}$ thick) of the implanted layer is composed of alumina platelets, while the core of the implanted layer is really composed of nanocrystallites. Therefore, the crystalline degradation is correlated with the ion distribution.

However, the question of the structure of this variety arises. We notice that $d_{2} / d_{1}=$ $0.265 / 0.153 \approx \sqrt{3}$, which can suggest a cubic structure with the following indexation: spot $1=$ $\{333\}$ and spot $2=\{300\}$, fixing the cubic parameter $a$ to $0.795 \mathrm{~nm}$. This suggestion has been considered because it is close to the cubic variety $\gamma$ and $\eta$ alumina (both having $a \approx 0.791 \mathrm{~nm}$ ). Spot 4 , in this assumption, would correspond to the $\{310\}$ plane, but spot 3 is not compatible with such a structure. Nevertheless, it could be due to the existence of a substructure since $d_{3} \approx 2 d_{1}$. However, it is clear that pattern 4 does not correspond exactly to $\gamma$ or $\eta$ alumina. Indeed, some lines of high intensity are absent (spots corresponding to $0.198 \mathrm{~nm}$ and $0.139 \mathrm{~nm}$ ) and some observed spots should be in extinction. Comparison with other alumina data has not been conclusive considering that only few information is available.

In conclusion of this approach, the crystallographic structure of the implanted layer is greatly damaged; it tends to be destabilized in a structure belonging very likely to the cubic system. 


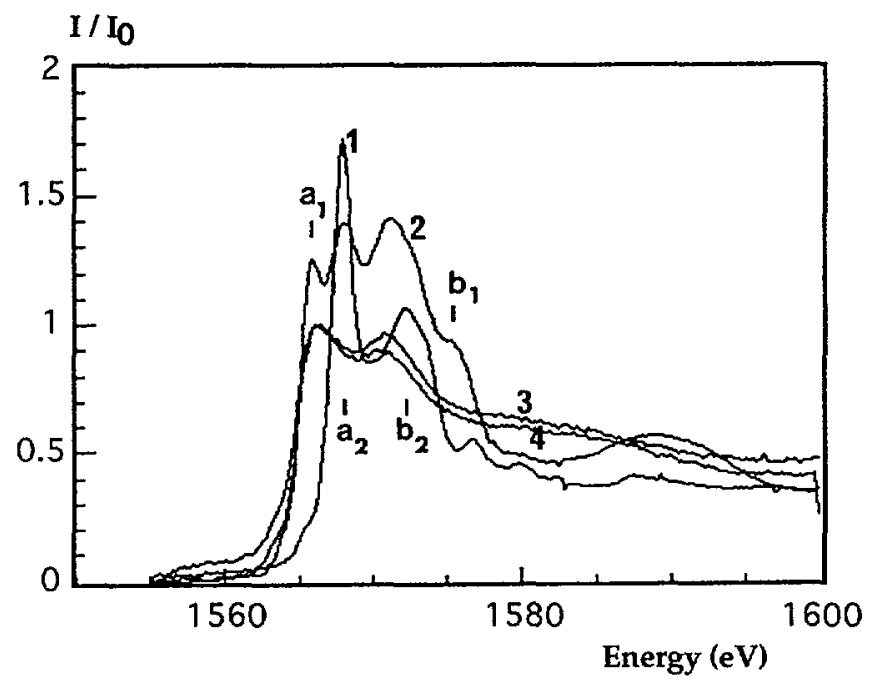

Fig. 3. - Aluminium threshold absorption (XANES spectra) measured using the total electron yield method for various alumina: 1) $\alpha$-alumina (polycrystalline), 2) $\gamma$-alumina (polycrystalline), 3) amorphous alumina, 4) $\alpha$-alumina implanted with $\mathrm{Cu}$ ions of $50 \mathrm{keV}$ at a fluence of $10^{17} \mathrm{at} \mathrm{cm}^{-2}$

In this case, it could be possible, with the XANES technique, to confirm or to invalidate the transformation of $\alpha$-alumina into a transition alumina variety ( $\operatorname{such}$ as $\gamma, \eta, \theta \ldots$ ) under the effect of ion irradiation. The structure of $\alpha-\mathrm{Al}_{2} \mathrm{O}_{3}$ is based on a close-packed arrangement of oxygen ions with aluminium ions occupying two-thirds of the octahedral sites. These sites (under the form of $\mathrm{AlO}_{6}$ octahedron) are not perfect; two independent $\mathrm{Al}-\mathrm{O}$ interatomic distances are present in the octahedron: 0.1971 and $0.1852 \mathrm{~nm}$ at $300 \mathrm{~K}[7,8]$. In $\gamma$ and $\eta$-alumina. aluminium ions are distributed on two kinds of sites: $68.7 \%$ in octahedral sites and $31.3 \%$ in tetrahedral sites for the $\gamma$-A12O3, $64.2 \%$ and $35.8 \%$, respectively for the $\eta-\mathrm{Al}_{2} \mathrm{O}_{3}$ [9]. Another crystallographic form, called $\theta$-alumina, presents some similarities in terms of XRD patterns. Its atomic structure is intermediate between the cubic close packing of the transitional $\gamma$, and $\eta$ aluminas and the hexagonally close-packed $\alpha-\mathrm{Al}_{2} \mathrm{O}_{3}$. In the $\theta$ variety, the octahedral and tetrahedral sites are equally partaged [9]. Hence, recording the XANES spectrum from the implanted samples gives the opportunity to detect a transformation of $\alpha$-alumina during implantation, in particular if it shows the presence of the tetrahedral sites.

Spectra presented in Figure 3 display the absorption K-edges of aluminum $(\approx 1567 \mathrm{eV})$ in various alumina structures. Curve (1) corresponds to $\alpha$-alumina (that used in this work) and shows two peaks, one which is well defined and named $a_{2}$, and another which is labelled $b_{2}$. These peaks are the signature of aluminium atoms in octahedral sites. Curve (2) presents the spectrum of a $\gamma$-alumina sample prepared by plasma deposition $[10,11]$. It has been confirmed by using $\mathrm{X}$-ray and electron diffraction techniques that this material corresponds well to the $\gamma$ spinel variety. A shift of the absorption threshold by $2 \mathrm{eV}$ towards low energies can be noticed. In addition to peaks $a_{2}$ and $b_{2}$, two less intense satellites $a_{1}$ and $b_{1}$ appear; they can be attributed to the occupation of tetrahedral sites by aluminium atoms. Moreover, an important decrease in the intensity of peak $a_{2}$ is also observed in comparison to the $b_{2}$ peak.

In the case of the alumina prepared by sputtering from $\alpha$-alumina using an ion gun, hereafter called amorphous, the absorption threshold (curve 3 ) is located at the same energy level 
Table III. - Thicknesses of different layers formed in alumina implanted by $\mathrm{Cu}, \mathrm{Zr}$ and $\mathrm{Fe}$ with energy ranging from 55 to $220 \mathrm{keV}$ at the fluence of $10^{17}$ at $\mathrm{cm}^{-2}$ determined from TEM analyses [13]. The projected ranges as well as the range stragglings of the implanted ions, calculated by TRIM [12] simulations, are also reported in the table for comparison.

\begin{tabular}{|c|c|c|c|c|c|}
\hline Ion & $\begin{array}{c}\text { Energy } \\
(\mathrm{keV})\end{array}$ & $\begin{array}{c}\text { Implanted layer } \\
\text { thickness (nm) }\end{array}$ & $\begin{array}{c}\text { Defect layer } \\
\text { thickness (nm) }\end{array}$ & $\begin{array}{c}\text { Ion projected } \\
\text { range (nm) }\end{array}$ & $\begin{array}{c}\text { Ion range } \\
\text { straggling (nm) }\end{array}$ \\
\hline $\mathrm{Cu}$ & 110 & 85 & 45 & 44 & 12 \\
& 220 & 160 & 70 & 85 & 20 \\
\hline $\mathrm{Zr}$ & 55 & 65 & 30 & 20 & 5 \\
& 110 & 80 & 40 & 35 & 8 \\
\hline $\mathrm{Fe}$ & 110 & 90 & 45 & 48 & 13 \\
\hline
\end{tabular}

(1565 eV) than that of $\gamma$-alumina. The first peak corresponds to $a_{1}$, while the second peak is a combination of $a_{2}$ and $b_{2}$ components. Thus, the amorphous state seems to correspond to a mixture of tetrahedral and octahedral sites. These sites are evidently perturbed as seen by the disappearance of the fine structure on spectrum 3. The XANES spectrum (curve 4 in Fig. 3) obtained in the case of an $\alpha$-alumina sample implanted with copper at a fluence of $10^{17}$ at $\mathrm{cm}^{-2}$ is somewhat similar to that of the amorphous $\mathrm{Al}_{2} \mathrm{O}_{3}$. This similarity is not sufficient to conclude that the implanted layer is amorphous due to the results of the TEMI observations mentionned above. Nevertheless, the XANES signal of the implanted sample can also be explained by a mixture of distorded tetrahedral and octahedral sites. For this sample, the difference between XANES and TEM results can be accounted for by the fact that the XANES signal is sensitive to the exact surrounding of the aluminium atoms while the electron diffraction signal is correlated to the site ordering of these atoms with a correlation length of the order of $1 \mathrm{~nm}$. Consequently, aluminum sites in the implanted alumina are distorted and certainly strained and imperfect but with a nanocrystalline structure.

\section{Discussion}

According to the physical mechanisms which occur during ion implantation, the irradiation damage changes the structural features of $\alpha-\mathrm{Al}_{2} \mathrm{O}_{3}$. For example, at $10^{17}$ at $\mathrm{cm}^{-2}$, the number of displacements per atom calculated by the TRIM-90 program [12] is about 200 for aluminium atoms and 50 for oxygen atoms. Obviously, the crystallographic structure of the substrate is damaged and could be modified. In fact, the TEM results have shown that the implanted layer has a strongly damaged crystallographic structure. This structural modification consists of a complex allotropic modification of the alumina lattice, initiated by some crystallographic defects. Such defects are numerous and tend to destabilize the $\alpha$-alumina into an ill-defined transition alumina.

Table III reports the thicknesses, as obtained from TEM analyses [13], of the various layers affected by the $\mathrm{Cu}, \mathrm{Zr}$ and Fe implantations, as well as the projected ranges and range stragglings of these ions deduced by TRIM simulations. Moreover, Figure 4 displays the ion profile as well as the nuclear and electronic energy loss distributions obtained by a TRIM simulation of the implantation of $\mathrm{Cu}$ of $110 \mathrm{keV}$ in $\alpha-\mathrm{Al}_{2} \mathrm{O}_{3}$. It is clear from Table III and Figure 4 that the thicknesses of the implanted layers measured by TEM agree nicely with those calculated 


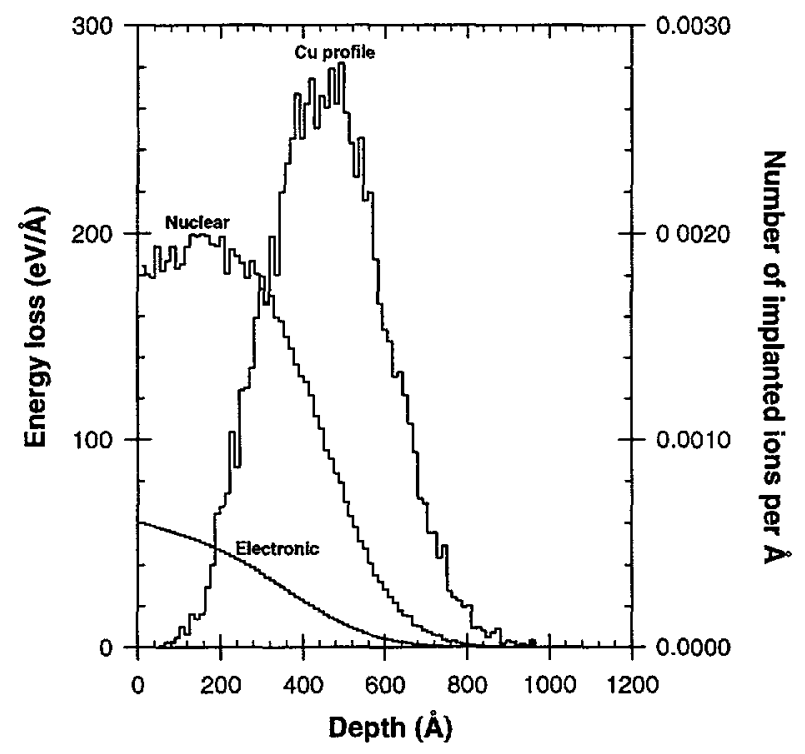

Fig. 4. - Implanted ion profile, nuclear and electronic energy loss distributions of the incident ion deduced from a TRIM [12] simulation of the implantation of $\mathrm{Cu}$ ions of $110 \mathrm{keV}$ in $\alpha$-alumina.

by the TRIM code. Furthermore, recent experiments performed in GANIL [14-16] have shown that electronic energy loss induces radiation damage in $\alpha$-alumina only for values exceeding $21 \mathrm{keV} / \mathrm{nm}$. These values are achieved only with heavy ions having several hundreds $\mathrm{MeV}$. Consequently, for the damage mechanisms of the implanted layers considered here, one can only retain nuclear collisions and the possible chemical effects of the implanted ions.

From the microscopic point of view, each impinging ion originates a displacement cascade consisting of sub-cascades $(\approx 20-30 \mathrm{~nm}$ in size in our case). Each of them constitutes a displacement spike (where the cristallographic arrangement is destroyed) which can lead to a local phase change (mechanism 1 ) by a rapid quenching of the moving atoms. The lattice is then reconstructed, giving rise to a $\gamma$-alumina variety. Such an effect is evidenced macroscopically in the preparation of polycrystalline $\gamma$-alumina by quenching $\alpha$-alumina directly from the melt [10]. This is the case of the preparation of sample 2 presented in Figure 3.

At the site where the ion comes to rest, steric as well chemical effects (due to an important distorsion of atomic bondings) can arise (mechanism 2). This process has, of course, a microscopic extension. However its accumulation by implanting at high fluences $\left(10^{17}\right.$ at $\left.\mathrm{cm}^{-2}\right)$ would lead to too high elastic stresses and chemical changes which could also induce phase transformation (like $\alpha \rightarrow \gamma$-alumina).

The defective layer is created without the direct contribution of any implanted ions (i.e. mechanisms 1 and 2 are no longer valid in this layer). Moreover, no point defect migration can be invoked to explain its formation since, according to Figure 1 and Table III, the implanted species are not present in this layer. Furthermore, it is not possible to explain its formation by recoil atoms coming from the implanted layer since these atoms go less deeper in the target than the majority of the implanted ions. This latter effect is clearly evidenced in Figure 5 which presents the profiles of the recoil atoms and of the implanted ions obtained by a TRIM simulation of the implantation of $110 \mathrm{keV} \mathrm{Cu}$ ions in $\alpha$-alumina. Consequently, the defective layer can only be induced by a stress effect at long distances. 


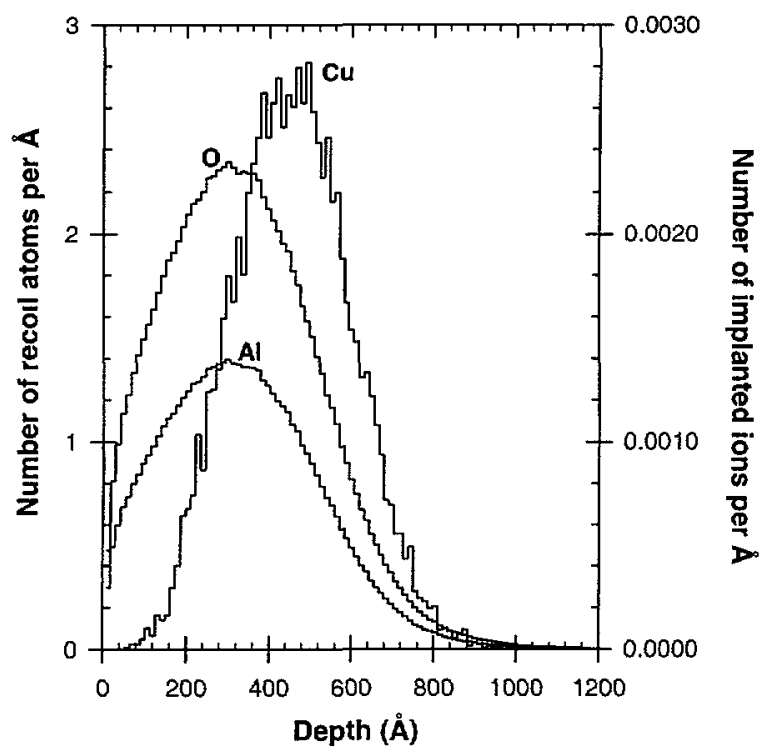

Fig. 5. - Implanted ion and recoil atom profiles obtained by a TRIM [12] simulation of the implantation of $110 \mathrm{keV} \mathrm{Cu}$ ions in $\alpha$-alumina.

In mechanism 1 , this long-range stress is due to the swelling induced by the $\alpha-\gamma$ transformation in the implanted layer. According to the JCPDS file, the relative density change is about $8 \%$ (3.99 and $3.67 \mathrm{~g} \mathrm{~cm}^{-3}$ for $\alpha$ and $\gamma$ phase respectively). In mechanism 2 it is more difficult to quantify such a swelling phenomenon due to the lack of knowledge about the exact site positions occupied by the implanted ions. Nevertheless, the values of the ionic radius of the different anions $\left(r_{\mathrm{Cu}^{+}}=0.096 \mathrm{~nm} ; r_{\mathrm{Cu}^{2+}}=0.062 \mathrm{~nm} ; r_{\mathrm{Fe}^{2+}}=0.076 \mathrm{~nm} ; r_{\mathrm{Fe}^{3+}}=0.064 \mathrm{~nm}\right.$; $\left.r_{\mathrm{Zr}^{4+}}=0.080 \mathrm{~nm} ; r_{\mathrm{Al}^{3+}}=0.05 \mathrm{~nm}\right)$ are a good indication for such a trend.

The question is: how does the defective layer form during ion implantation? It is probably built by a propagation mechanism of structural defects (dislocations, stacking faults) generated in the implanted layer. Within mechanism 1 , the $\alpha-\gamma$ transformation induced in each subcascade gives rise to a local plasticity (swelling of $8 \%$ ) leading to a nucleation and propagation of extended defects. During implantation, these extended defects propagate at long distances under the stresses arising from the apparition of new transformed regions. This effect saturates when the implanted layer is completely transformed. In the case of mechanism 2, the accumulation of the local stresses generated around each implanted ion can induce a similar nucleation and propagation mechanism of extended defects above a certain fluence.

An examination of Table III shows that the thickness of the defective layer is strongly influenced by the ion energy and that it is nearly the half of the implanted one whatever the implantation conditions (ion, energy). At the implantation energy of $110 \mathrm{keV}$, the thickness of the defective layer does not depend strongly on the chemical nature ( $\mathrm{Cu}, \mathrm{Fe}$ or $\mathrm{Zr}$ ) and hence on the ionic radius of the implanted ion. Moreover, for the same ion species and the same ion fluence, the accumulated stresses invoked in mechanism 2 (and resulting from steric and chemical effects) are expected, at a first order, not to change when the ion energy is modified. As seen in Table III, this is obviously not the case, and consequently, mechanism 2 has to be ruled out for the explanation of the formation of the defective layer. Furthermore, it is well 
known that the total number of displaced atoms as well as the thickness of the implanted layer increase almost linearly with the ion energy. Therefore, within mechanism 1 , it is obvious that the thickness of the defective layer will increase accordingly, as shown in Table III.

\section{Conclusion}

The microstructure of polycrystalline $\alpha$-alumina samples implanted with different metallic elements were analyzed by both transmission electron microscopy and XANES techniques. We have observed that the near surface region is composed of the implanted layer and a defective layer localized well beyond the range of the implanted ions.

The crystallographic structure of the implanted layer is strongly damaged and can be seen as a mixture of the transitional alumina varieties. The aluminium sites are very distorted and strained, some of them having a tetrahedral character.

We have shown that the formation of the defective layer can be understood as a result of the propagation of the extended defects created in the implanted layer. In fact, ion irradiation produces point defects, extended defects and especially $\alpha$ to $\gamma$ phase transformation leading to an important swelling $(\approx 8 \%)$ of the implanted layer and then to a high level of internal stresses. These stresses are able to provide an efficient driving force for the propagation of the extended defects beyond the implanted layer.

New experiments, performed at low fluences, are now in progress. They could provide interesting information about the early stages of the formation of the defective layer.

\section{Acknowledgments}

The authors are grateful to A. Plantier who performed the ion implantations with the ion separator of the Institut de Physique Nucléaire de Lyon, A.M. Flank for the experimental support at LURE, and DRET (Direction des Recherches des Études Techniques) for its financial support.

\section{References}

[1] White C. W., McHargue C. J., Sklad P. S., Boatner L. A. and Farlow G. C., Mater. Scz. Reports 4 (1989) 41-146.

[2] McHargue C.J., "Structure property relationships in surface-modified ceramics". C.J. McHargue, R. Kossowsky and W.O. Hofer, Eds. (Kluwer, 1989) pp. 253-310.

[3] Pells G.P. and Stathopoulos A.Y., Radrat. Effects 74 (1983) 181-191.

[4] Sklade P.S., McHargue C.J., White C.W. and Farlow G.C., High Tech. Ceramics (1987) 1073-1082.

[5] Rahioui A. and Esnouf C., Surf. Coat. Techn. 45 (1991) 23-31.

[6] Donnet C., Marest G., Moncoffre N., Tousset J., Rahioui A., Esnouf C. and Brunel M., Nucl. Instrum. Methods B 59/60 (1991) 1205-1210.

[7] Megaw H. D., "Crystal structure - A working approach". Philadelphia, Pennsylvania: Saunders (1973) pp. 226-236.

[8] Ishizawa N., Miyata T., Minato I., Marumo F. and Iwai S., Acta Cryst. B 36 (1980) 228-230.

[9] Zhou R.S. and Snyder R.L., Acta Cryst. B 47 (1991) 617-630. 
[10] Carrerot A., Rieu J., Thollet G. and Esnouf C., Texture analysis in alumina plasma sprayed coatings, Proc. 9th Inter. Conf. on texture of materials ICOTOM9 (SF2M, Ed., Avignon, 17-19 Septembre 1990) 8p.

[11] In the plasma spraying process, $\alpha-\mathrm{Al}_{2} \mathrm{O}_{3}$ powders are injected in a plasma flame where they are changed into molten droplets. Droplets are shot on to a grit-blasted metallic substrate where they splash, cool and solidify. The microstructure of alumina plasma sprayed coatings is formed of few hundred micrometers thick overlapping of solidified platelets (diameter is about $30 \mathrm{~mm}$ ).

[12] Ziegler J.F., Biersak J.P. and Littmark U., "The Stopping and Ranges of Ions in Matter", J.F. Ziegler, Ed. (Pergamon Press, 1985).

[13] Rahioui A., Ph. D. thesis, INSA de Lyon, (1993) pp. 80-104.

[14] Canut B., Ramos S.M.M., Thévenard P., Moncoffre N., Benyagoub A., Marest G., Meftah A., Toulemonde M. and Studer F., Nucl. Instrum. Methods B 80/81 (1993) 1114.

[15] Marty J. M., Benyagoub A., Marest G., Moncoffre N., Toulemonde M., Meftah A., Studer F., Canut B., Ramos S.M.M. and Thévenard P., Nucl. Instrum. Methods B 91 (1994) 274.

[16] Canut B., Benyagoub A., Marest G., Meftah A., Moncoffre N., Ramos S.M.M., Studer F., Thévenard P. and Toulemonde M., Phys. Rev. B 51 (1995) 12194. 